\title{
Análise sobre a opção de curso de graduação em Tecnologia em Cosmetologia e Estética pelas discentes da UninCor
}

\author{
Letícia Caixeta Vieira RIBEIRO ${ }^{1}$ \\ Alexandra Azevedo de CARAVALHO ${ }^{2}$ \\ Fernanda Augusta Marques PINHEIRO ${ }^{3}$ \\ Jeanete Moussa ALMA ${ }^{4}$
}

${ }^{1}$ Graduada em Cosmetologia e Estética, Universidade Vale do Rio Verde- UNINCOR

${ }^{2}$ Graduada em Fisioterapia, Universidade Vale do Rio Verde - UNINCOR Fisioterapeuta, Mestre em Educação,

Professora e Coordenadora do Curso de Cosmetologia e Estética/UNINCOR-.alexandrafisio2004@yahoo.com.br

${ }^{3}$ Graduada em Fisioterapia, Universidade Vale do Rio Verde - UNINCOR - Orientadora do trabalho.

${ }^{4}$ Biomédica, Técnica em Estética Facial e Corporal, Mestre em Educação, Doutora em Reabilitação pela UNIFESP, Professora e Coordenadora do Curso de Pós-Graduação em Estética Integral/ Universidade Gama Filho - orientadora do trabalho. contato.especiariascosmeticas@gmail.com

\section{Recebido em: 21/05/2013 - Aprovado em: 30/07/2013 - Disponibilizado em: 15/08/2013}

\section{Resumo}

A escolha profissional envolve fatores psicológicos, familiares, educacionais, sociais, econômicos e políticos. A fim de buscar conhecimento e prática no que diz respeito à beleza e autoimagem, jovens buscam cursos superiores mais direcionados para ingressar na carreira profissional. Sentir-se bem e seguir tendências em que o mundo engloba, são objetivos dos profissionais da área da estética, da beleza e moda. São áreas amplas com um retorno financeiro satisfatório para a maioria dos profissionais. O objetivo desta pesquisa é identificar no perfil dos alunos do curso de Tecnologia em Cosmetologia e Estética da Universidade Vale do Rio Verde - UNINCOR, as características pessoais, motivacionais que mais influenciaram na escolha por este curso analisando os interesses e expectativas de mercado depois de formados. A pesquisa será desenvolvida através de análises bibliográficas e estudo de campo, com aplicação de questionário aos acadêmicos, regularmente matriculados no curso de graduação de Tecnologia em Cosmetologia e Estética da Universidade do Vale do Rio Verde de Três Corações - UNINCOR. Desta forma este estudo se enquadra como uma pesquisa exploratória com abordagem quali-quantitativa. Os resultados esperados por essa pesquisa irão demonstrar quais são os valores intrínsecos e extrínsecos que influenciaram na escolha do curso, bem como se o crescente mercado da estética e beleza influencia na opção pelo curso. Esta pesquisa tem relevância por trazer dados científicos tanto para nós pesquisadoras como para todo o trade educacional que organiza as políticas públicas curriculares das universidades a fim de refletir sobre as características pessoais e motivacionais perante as escolhas dos cursos superiores.

Palavras-chave: Profissão. Cursos superiores. Motivação. Estética. Perfil Acadêmico.

\begin{abstract}
The professional choice involves psychological, familial, educational, social, economic and political. In order to seek knowledge and practice with regard to beauty and self-image, young people seeking higher education more targeted to join the career profissional.Sentir well and following trends in the world that encompasses the goals are professionals from aesthetics, beauty and fashion. Are large areas with a satisfactory financial return for most professionals. The goal of this research is to identify the profile of the students of Technology in Cosmetology and Esthetics University Vale do Rio Verde-UNINCOR, personal characteristics, motivational affects most choose this course by analyzing the interests and expectations of the market after graduation. The research will be developed through analysis and bibliographic field study with a questionnaire to students, enrolled in undergraduate degree in Technology Cosmetology and Aesthetics at the University of Vale do Rio Verde Three of Hearts - UNINCOR. Thus this study qualifies as an exploratory approach with qualitative and quantitative. The expected results of this research will demonstrate what values are intrinsic and extrinsic factors that influenced the choice of the course, as well as the growing market of aesthetic beauty and influences the choice of course. This research has relevance for bringing scientific researchers both for us and for all the trade that organizes educational public policy curriculum of universities to reflect on the personal characteristics and motivation towards the choices of courses.
\end{abstract}

Keywords: Job. Courses. Motivation. Aesthetics. Academic Profile. 


\section{Introdução}

A escolha profissional envolve fatores psicológicos, familiares, educacionais, sociais, econômicos e políticos. As variações psicológicas que acercam o processo de escolha profissional são os interesses, habilidades, traços de personalidade, expectativas e valores individuais em relação ao futuro profissional e a maturidade (ALVES; SILVA, 2008).

A fim de buscar conhecimento e prática no que diz respeito à beleza e auto imagem, as pessoas buscam cursos superiores mais direcionados para ingressar na carreira profissional. O prazer pela profissão ou a posição financeira que tais cursos proporcionam é o grande foco da maioria das pessoas. Sentir-se bem e seguir tendências em que o mundo engloba, são objetivos dos profissionais da área da estética, da beleza. São áreas amplas com um retorno financeiro satisfatório para a maioria dos profissionais. (SASAKI; TAVARES; VELHO, 2008)

\section{O segmento produtivo representado} pela área da Estética e Cosmética tem avançado com a ampliação de indústrias, novos equipamentos, novas técnicas de trabalho, novas faixas de consumidores, com maior exigência, buscando serviços e produtos para embelezamento, recuperação e manutenção da saúde na área de estética, e a democratização de acesso aos insumos, exigem crescente qualificação dos profissionais da área.
Com a demanda existente no mercado por profissionais capacitados, cresce o número de cursos voltados para a área de estética, o que exige formação e profissionalismo, pois além da beleza, trata-se também da saúde e do bem-estar das pessoas.

Áreas de competitividade e dinamismo, onde em uma sociedade mediatizada do século XXI, a imagem desempenha um papel crucial, a moda e o corpo expressam a sua pluralidade em termos de valores estéticos. Não se tratando apenas de conhecimento próprio, as pessoas que buscam os cursos de Tecnologia em Cosmetologia e Estética, por exemplo, se tornam aptos a exercer uma carreira profissional que muitas vezes também geram satisfação pessoal antes mesmo da profissional por estarem interligadas a sentimentos de melhora da sua autoestima, da auto-confiança e da sua imagem visual. (PONTE, 1998)

Este projeto de pesquisa propõe-se a identificar no perfil dos alunos do curso de Tecnologia em Cosmetologia e Estética da Universidade Vale do Rio Verde de Três Corações - UNINCOR, as características pessoais, motivacionais que mais influenciaram na escolha por este curso, ressaltando a importância de valores intrínsecos de realização pessoal com a profissional.

A escolha profissional é um processo em que as pessoas ficam diante das responsabilidades que passa a assumir na 
definição do seu futuro como cidadão. As práticas educativas que estão presentes nas famílias e no sistema de ensino, não os preparam para tomar decisões, não os exercitam para examinar os valores, interesses e aptidões que caracterizam sua individualidade e também não oportuniza uma análise sistemática e reflexiva do mundo do trabalho na sua complexidade. Muitas vezes as pessoas acabam por fazer opções insatisfatórias devido à carência de um projeto de vida, utilizando fantasias e um baixo senso de realidade (MAGALHAES; REDIVO, 1998).

De acordo com Moura e Menezes (2004), a escolha profissional deve ser feita de forma amadurecida, onde a pessoa analisa, observa e consegue adquirir conhecimentos sobre todos os aspectos que acercam, a situação onde o indivíduo se encontra. Enxergando as vantagens e desvantagens das suas opções, consegue então fazer a sua decisão. Mas na maioria das vezes não é o que acontece, as escolhas profissionais são feitas na ausência de tais critérios ou de critérios pouco consistentes, onde há pouca busca de informação, há uma visão distorcida ou idealizada, acerca das opções profissionais, o que pode produzir posteriormente decepções e arrependimentos com o curso escolhido. As decepções geralmente estão vinculadas ao caráter teórico das disciplinas cursadas, e a falta de uma visão da prática profissional.

Ao fazer uma escolha profissional madura entende-se que a pessoa possui uma boa capacidade de adaptação, interpretação da realidade, discriminação, sabe analisar os conhecimentos sobre si e sobre as realidades profissionais. A maturidade para a escolha profissional esta composta por atitudes e conhecimentos. Os interesses das pessoas variam muito, acredita-se que as pessoas não fazem as mesmas coisas pelas mesmas razões. É nessa variedade de interesses que se encontra uma maneira de compreender um fenômeno paradoxal a motivação humana. (BERGAMINI, 1990).

Para se aproximar de uma definição do termo motivação encontrou-se a origem da palavra, no latim motivu, que significa que pode fazer mover ou que se move. O termo pode ser entendido como uma tendência para a ação, que tem origem e um motivo, esse motivo é o que faz a pessoa se movimentar ou agir (PEREIRA; FÁVERO, 2001).

A satisfação pode ser entendida como um sentimento de identificação pessoal. A inserção em atividades acadêmicas costuma ser associada à uma maior identidade profissional percebida, pois é no campo de trabalho que o aluno descobre sua real satisfação e prazer (SPARTA; GOMES, 2005).

A secularização atribuiu um novo estatuto de características humanas, fazendo com que a imagem caracterizasse uma exposição involuntária de emoções, revelando o "eu" a vida publica. Em 1830 a mulher passa a ser responsável pela imagem publica, pelas formas mais expostas em publico, a 
moda foi um agente de transformação, o narcisismo e o desejo estético projetaram homens e mulheres desde então (SASAKI; TAVARES; VELHO, 2008).

$\mathrm{O}$ aumento pelo interesse na continuidade dos cursos e o engajamento em atividades acadêmicas é fundamental para a satisfação e o comprometimento. Então o momento que vai chegando ao término do curso, que se dá quando a qualidade das atividades exercidas e a avaliação da formação produzem expectativas quanto à atuação profissional. A fase de conclusão pode ser a chamada fase de responsabilidade, onde o aluno deixa a universidade e é convocado a atuar dentro do seu campo de trabalho (PONTE, 1998).

A formação profissional esta associada á um individuo frequentar cursos de graduação. Já o desenvolvimento profissional é á pratica de atividades como projetos, troca de experiências, atividades em grupos, preparando melhor para a carreira e o dia-adia do profissional. A autoconfiança e autonomia são fatores relevantes ao aluno que busca sua identidade profissional. Um dos aspectos que mais contribui para a formação de identidade é a forma como o aluno ingressa na profissão. $\mathrm{O}$ aspecto que mais contribuem para a formação de identidade é a forma de como inicia-se na profissão desejada. A formação especializada e avançada,continua a ser um suporte fundamental do desenvolvimento profissional. Permitindo uma variedade de percursos e processos de desenvolvimento profissional, é na formação que se deve constituir um objeto fundamental de investigação no terreno educativo, visar os desafios que ficaram nas instituições (PONTE, 1998).

Quando jovens e adultos precisam tomar decisões como á qual carreira seguir, determinarão automaticamente uma identidade pessoal. Essa identidade pessoal, engloba satisfação profissional, aspectos pessoais, vocacionais e contextuais da realidade do trabalho, sendo possível definir que a satisfação profissional do indivíduo, a sua motivação e realização, é resultante do seu trabalho, expressando os próprios valores e interesses (SASAKI; TAVARES; VELHO, 2008)

No mundo contemporâneo a vaidade é uma preocupação contínua. As pessoas chegam ao ponto de ligarem suas realizações pessoais aos ideais ditados pela vaidade. Os valores como inteligência, elegância se tornam inferiores, há uma inversão de valores onde a vaidade se torna o foco principal das pessoas atingindo todas elas desde grandes profissionais até inocentes crianças. A vaidade é a paixão que faz as pessoas se sentirem superiores, ela constitui a própria identidade, faz parte do eu de cada um. Há a vaidade que motiva, como a vontade de querer vencer, crescer, ela faz o indivíduo buscar forças e resistências para concluir o que deseja (SILVA, 2009).

Numa sociedade onde a cultura influencia e muito no que titulam de corpo 
perfeito, A estética ganhou e atingiu patamares altos, onde de acordo com o avanço do mercado e a maior exigência do mercado consumidor, houve a necessidade de especialização e estudos na área (SILVA, 2009).

Dessa forma o curso de Tecnólogo em Cosmetologia e Estética apesar de recente, já abriga grande número de formandos $\mathrm{e}$ graduandos, que atuam na área e que cada vez mais buscam maior capacitação profissional.

\section{Materiais e métodos}

O presente estudo será desenvolvido em duas etapas, a primeira constituída de análises bibliográficas, com consultas a livros, periódicos, legislações e demais bibliografias relacionadas à temática aludida. Seguindo-se de estudo de campo, no curso de graduação de Tecnologia em Cosmetologia e Estética da Universidade do Vale do Rio Verde de Três Corações, através da aplicação de um questionário contendo vinte e nove perguntas fechadas aos acadêmicos do $2^{\circ}$., $3^{\circ} ., 4^{\circ}$. e $6^{\circ}$. períodos, regularmente matriculados.

Para realização deste estudo, foi solicitado autorização junto a coordenação do respectivo curso. Os sujeitos participantes da pesquisa assinaram um termo livre de consentimento e esclarecimento concordando em participar

Desta forma este estudo se enquadra como uma pesquisa exploratória com abordagem quali-quantitativa. A pesquisa exploratória é aquela realizada em áreas que há pouco ou nenhum conhecimento sistematizado sobre o assunto em questão, tem como foco a investigação de fenômenos . Tem como objetivo o levantamento de hipóteses de assuntos que são pouco explorados, identificando dados que possam desenvolver uma abordagem.

As pesquisas qualitativas estimulam os entrevistados a pensarem livremente sobre algum tema, objeto ou conceitos, elas atingem motivações não explicítas de maneira espontânea. Já as pesquisas quantitativas apuram opiniões e atitudes explicítas e conscientes das pessoas entrevistadas, utilizam documentos como questionários.

\section{Resultados e Discussão}

Os resultados da pesquisa depois de tratados estatisticamente foram convertidos nos seguintes gráficos:

Gráfico 1 - Diferença do sexo nesta pesquisa mulheres/homens.

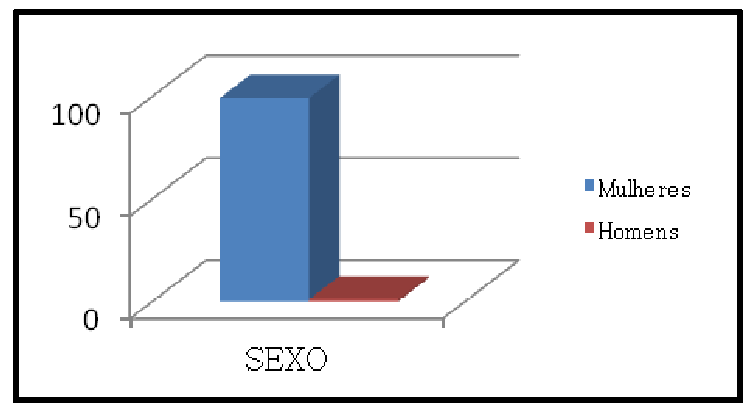

Fonte: os autores

Gráfico 1 - A diferença entre os dois valores é de significância, onde ainda hoje as 
mulheres predominam no setor da estética, talvez por certo preconceito do sexo masculino. O que ainda aparenta ser arcaica é a idéia de o trabalho estético ser exclusivamente para a classe feminina, sendo esta uma rotulação difícil de quebrar.

$\mathrm{Na}$ atualidade percebemos que o universo masculino está em desenvolvimento continuo, sendo ainda pouco explorado, no mercado da estética e da beleza, por falta de conhecimento, ou por falta de conscientização das reais necessidades que os homens necessitam para se embelezar, sem serem discriminados. (PEREIRA, Patrícia Guimarães, Vaidade Masculina - Novo segmento de mercado para os profissionais da estética).

Gráfico 2- Distribuição por idade.

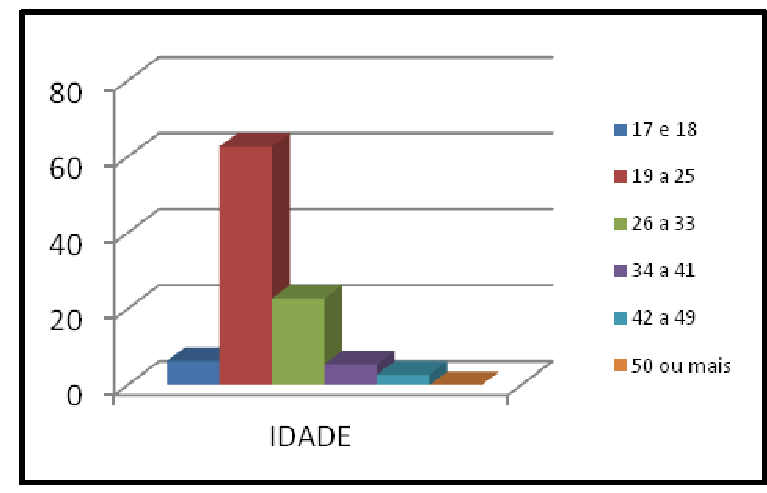

Fonte: os autores

Gráfico 2- No gráfico acima, podemos visualizar uma significativa diferença entre as faixas etárias, se sobressaindo às idades de 19 a 25 anos, normalmente quando ocorre a mudança de ensino médio para o ensino superior. De acordo com o Instituto Brasileiro de Geografia e Estatística (IBGE), a distribuição percentual de estudantes de 18 a 24 anos se faz da seguinte forma: 10,7\% no ensino fundamental; $34,9 \%$ no ensino médio e $42,8 \%$ no superior (IBGE, 2008).

Gráfico 03- Distribuição por Tipo de formação

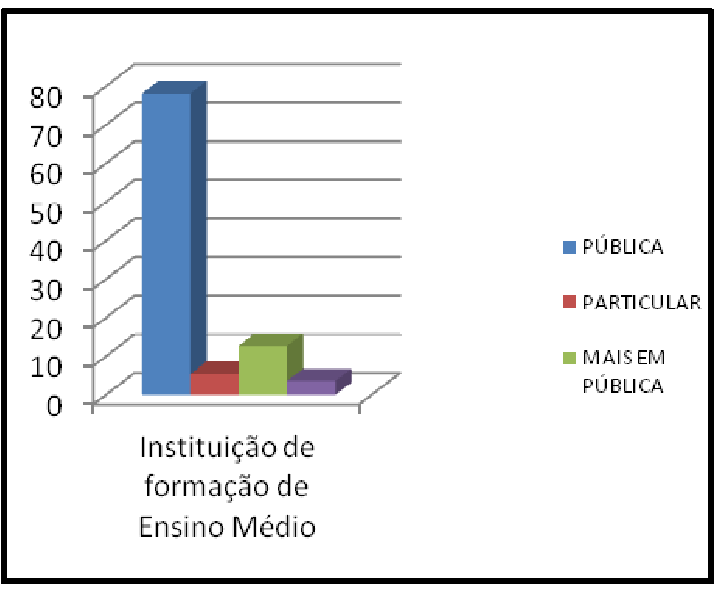

Fonte: os autores

Gráfico 03- Na região e por motivos diversos, financeiros ou não grande parte dos entrevistados cursou escola pública comprovando assim ainda o forte desejo de cursar o ensino superior. A maioria dos estudantes brasileiros termina o ensino médio em escolas públicas. O dado é da Pnad (Pesquisa Nacional por Amostra de Domicílios) 2009, pelo IBGE (Instituto Brasileiro de Geografia e Estatística). Segundo o Pnad 2009, 86,9\% (ou quase 31 milhões de pessoas) dos estudantes com 4 anos de idade ou mais estavam em um estabelecimento da rede pública. Outros $13,1 \%$ (4,5 milhões) estavam na rede particular. 
Gráfico 04- Distribuição da motivação que levaram os entrevistados a optarem pelo curso

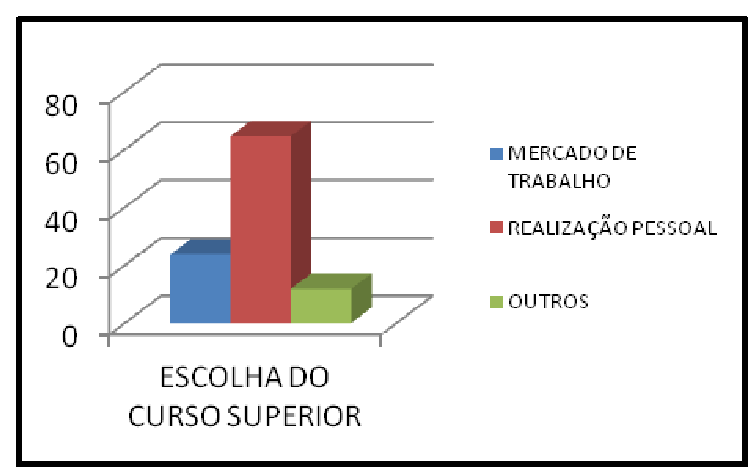

Fonte: os autores

Gráfico 04- No gráfico acima o resultado mostra que mais de $60 \%$ dos entrevistados procuram fazer uma graduação para realizarem suas expectativas pessoais, procurando uma felicidade interior. A felicidade oriunda do trabalho resulta da satisfação plena de necessidades psicossociais, do sentimento de prazer e do sentido de contribuição no exercício da atividade profissional (MARTINEZ MC, 2002, p.59).

\section{Gráfico 05- Distribuição pela influencia na escolha}

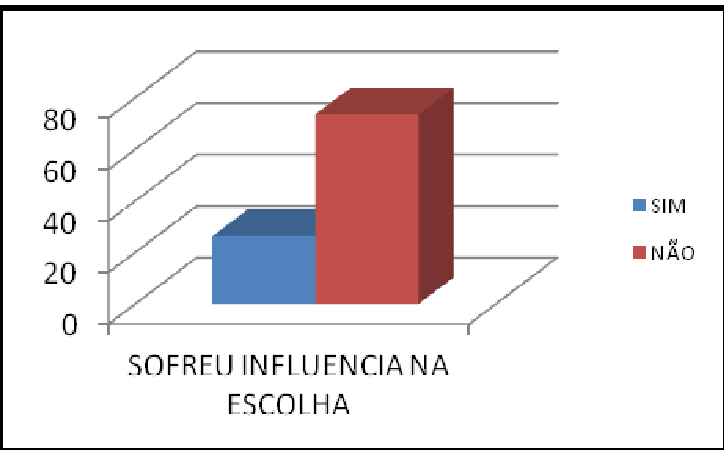

Fonte: os autores

Gráfico 05- O gráfico nos mostra que maioria dos entrevistados segue este padrão escolheu por vontade própria e realização própria.

Hoje em dia os estudantes não tem mais levado em consideração influencia familiar tendo estes a questão de satisfação profissional já bem esclarecida. Buscam a profissão com a qual mais se identificam mais raramente seguem a vontade de outra pessoa. (IBGE, 2009);

Gráfico 06- Influência na escolha dos entrevistados

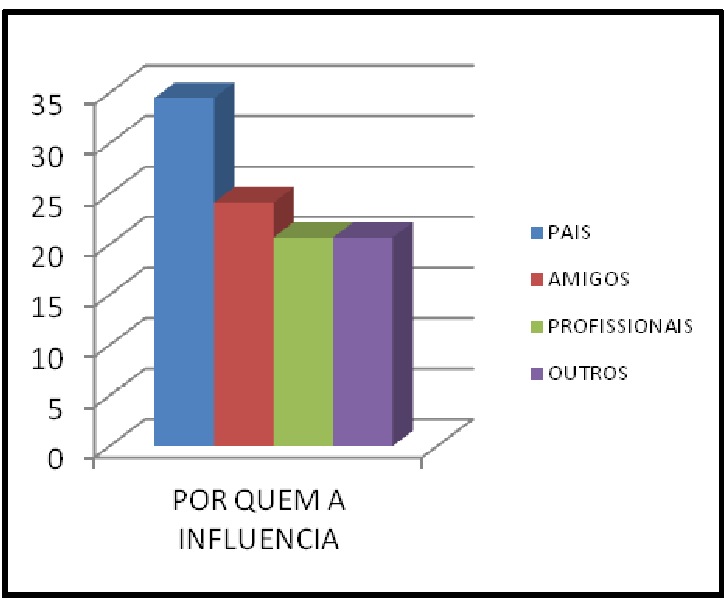

Fonte: os autores

Gráfico 06 - A diferença dos resultados aparece bem ressaltada quanto a influencia dos pais. De acordo com um estudo realizado pela Universidade Federal da Bahia, embora alguns estudantes afirmassem que a identidade profissional foi a responsável pela escolha do curso superior, a maior parte deles reconheceu que há inúmeros fatores que interferem neste processo, dentre eles, a influência e a expectativa dos pais. (GONDIM, Sônia Maria, Perfil profissional e mercado de trabalho: relação com a formação Acadêmica). 
Gráfico 07- Procura por investimento menor comparado a outros cursos

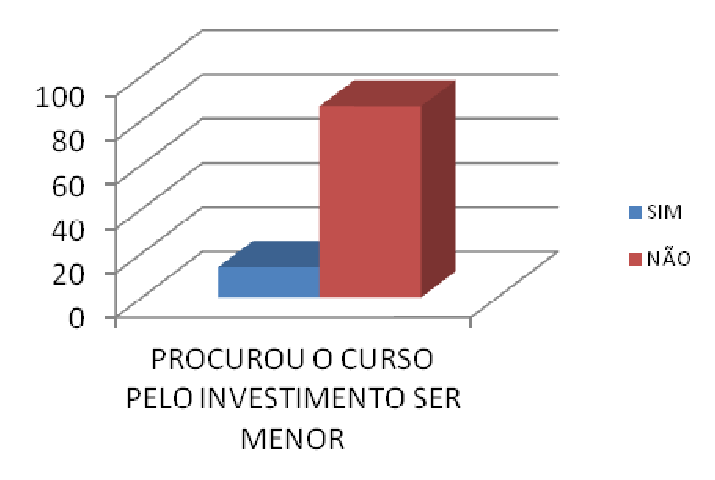

Fonte: os autores

Gráfico 07- Os cursos de menor custo são atrativos, mas outros itens são levados em consideração na hora da escolha como duração do curso, grade curricular dentre outros.

O investimento a se seguir pode parecer ao inicio de pesquisa sobre Universidades importante, mas o aluno quando este está decidido a seguir determinado curso dificilmente abrirá mão do mesmo. (VEJA/2008);

Gráfico 08- Vaidade influenciou na escolha

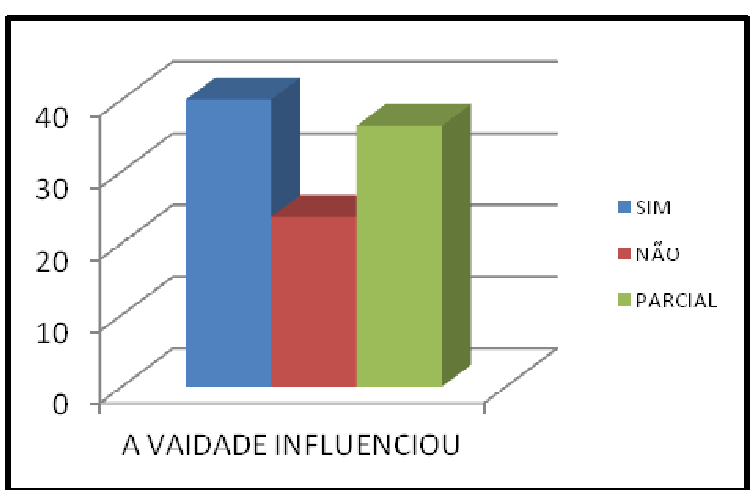

Fonte: os autores
Gráfico 08- Quando se escolhe algo que se gosta de fazer jamais se tem de trabalhar. E é nesta questão que muitos alunos tem se baseado na hora da escolha profissional avaliando e buscando a maior gama de informações possíveis sobre o assunto. (VEJA, 2008);

Gráfico 09- Contribuição do curso na imagem visual

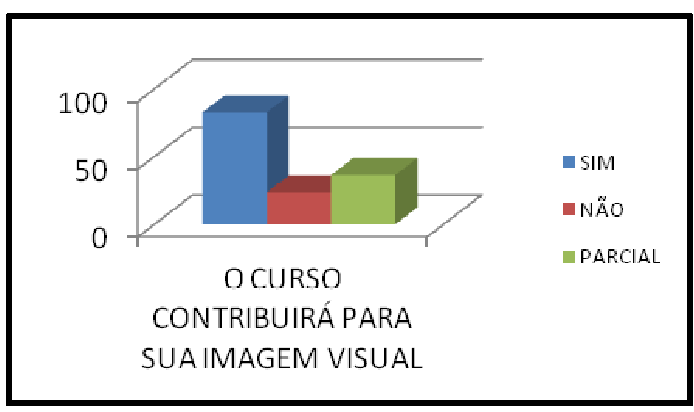

Fonte: os autores

Gráfico 09- A vaidade dos alunos e novamente a afinidade destes com o curso os faz aplicar os conhecimentos adquiridos no curso em sua autoimagem, o que de certa forma os obriga a estar sempre com esta apresentável.

Com os conhecimentos adquiridos pode-se embasá-los na vida e até mesmo aplicá-los ao seu dia a dia. (SEBRAE/ENFOQUE PROFISSIONAL, 2009). 
Gráfico 10- Distribuição das expectativas do curso

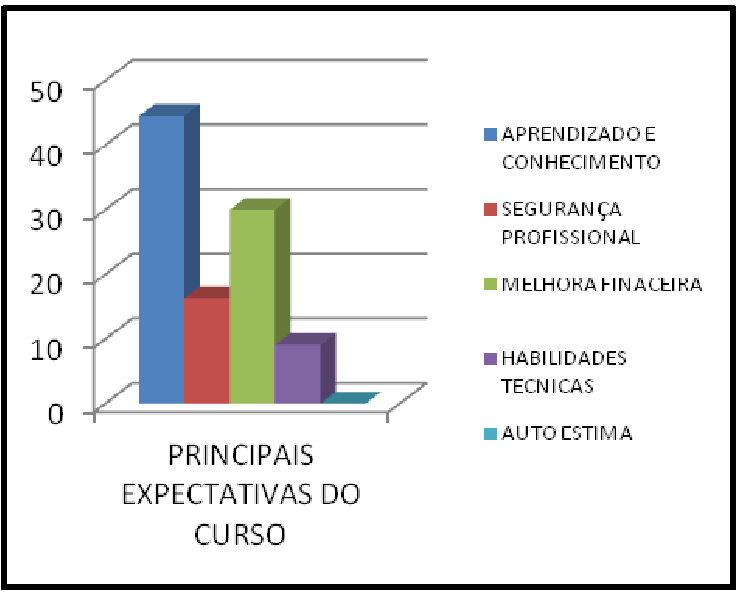

Fonte: os autores

Gráfico 10- A área da estética por estar em alta e o publico feminino ser em sua maioria consumidor, atrai cada vez mais alunos para os cursos de beleza e estética fazendo com que o aprendizado seja aprimorado e o retorno financeiro seja maior.

O aprendizado e a estabilidade profissional caminham juntos, estes oferecem cada vez mais interesse dos jovens. Um emprego no qual também se alcança a melhora financeira traz satisfação e vontade de crescer dos funcionários; assim sendo há maior especialização e crescimento empresarial;( SEBRAE/2010).
Gráfico 11- Conteúdo que motivou na escolha do curso

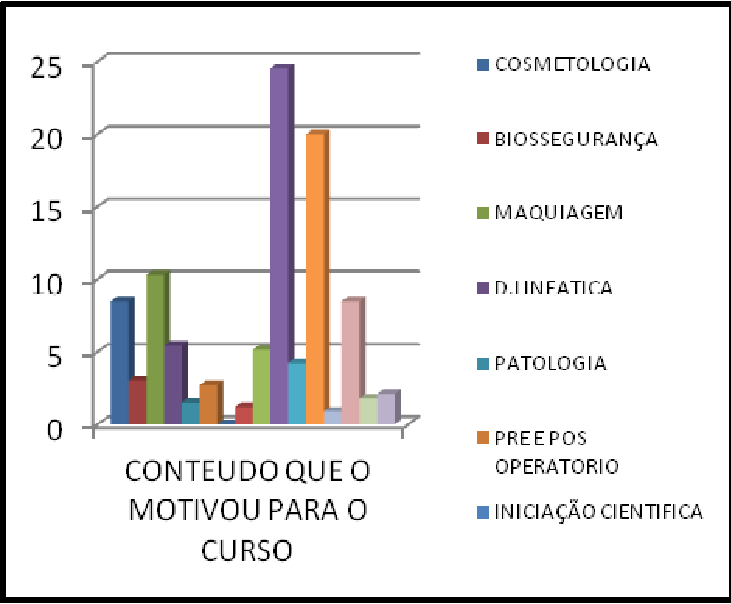

Fonte: os autores

Gráfico 11- O consumo com a beleza está à frente de outras despesas consideradas essenciais é muito grande o que provoca o interesse dos alunos ainda mais na estética corporal que é um enfoque grande do publico. Uma das razões mais plausíveis para o crescimento deste setor deve-se à expansão dos centros de formação profissional de beleza por todo o território nacional. Quanto mais profissionais no mercado, mais salões de beleza são abertos diariamente, além de clínicas estéticas e próprios negócios suprindo a intensa demanda de serviços existente em todas as regiões. Cursos de cabeleireiro, manicure e pedicure, depilação, massagens e agora o superior de Tecnologia em Cosmetologia e Estética, também ensinam técnicas de negociação e estimulam o empreendedorismo. Consequentemente, os estudantes tendem a investir no próprio negócio logo que o diploma chega às mãos. Estudo recente da Fecomércio São Paulo, com dados extraídos do IBGE, apontou que o 
gasto mensal das famílias com serviços de cabeleireiro e massagens ultrapassou a marca de R\$ 1 bilhão, um crescimento de $44 \%$ em seis anos. (IBGE).

Gráfico 12 - Perspectiva de cursos depois de formadas

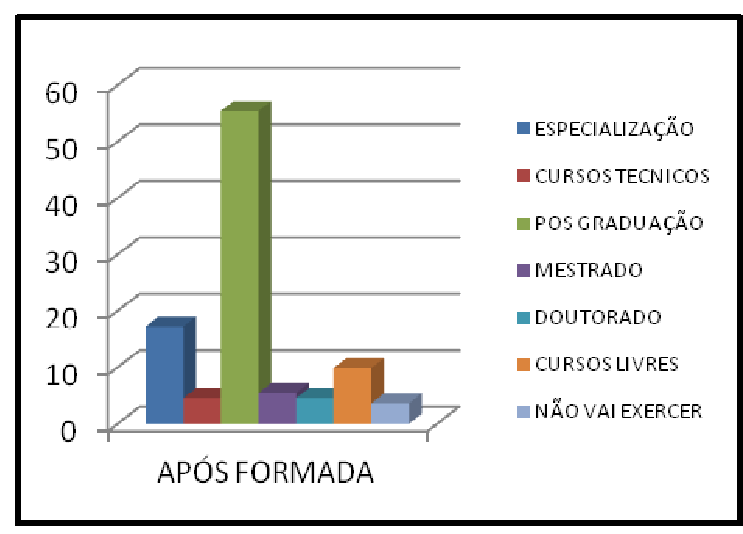

Fonte: os autores

Gráfico 12- O gráfico acima mostra que $55 \%$ depois de formado desejam ingressar numa pós-graduação, para mais qualificação e conhecimento A especialização e a continuação dos estudos ainda mais agora com incentivos governamentais têm aumentado a procura por curso de pósgraduação, o que tem animado a comunidade estudantil de maneira geral. (SEBRAE/2010); com o aumento de profissionais na área da estética, tende haver maior procura e maior desejo de capacitação profissional que a dez anos atrás. $\mathrm{O}$ mercado mais competitivo induz a qualidade em serviços só acrescentando ao mercado consumidor.
Gráfico 13- Perspectiva de emprego depois de formadas

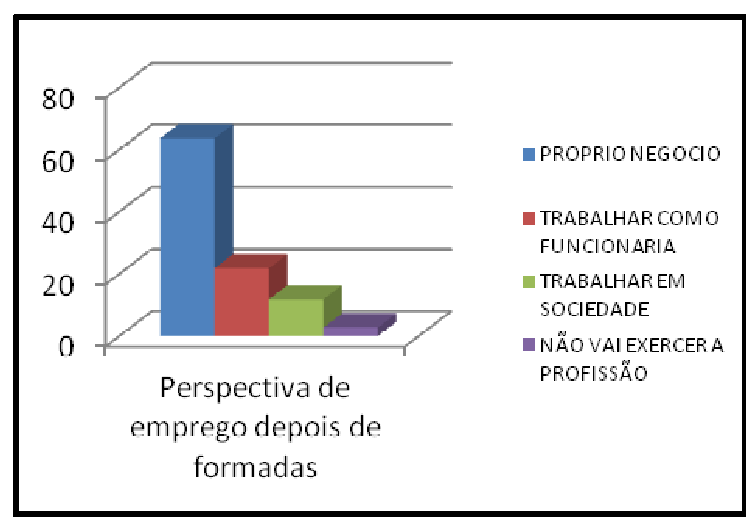

Fonte: os autores

Gráfico 13- Muitos acadêmicos têm seus incentivos profissionais ainda na faculdade onde com a afinidade entre colegas de classe surge a oportunidade do próprio negocio. (SEBRAE, 2011); Com os custos a menos, a dificuldade de começar e se lançar nome no mercado de trabalho a sociedade tem gerado caminhos fáceis a recém formados, tendo estes maiores oportunidades juntos que separados. Com este mercado em alto crescimento a expectativa de dos entrevistados depois de formadas é de abrir seu próprio negocio, visando um reconhecimento profissional.

\section{Conclusão}

$\mathrm{O}$ resultado da pesquisa salienta que valores intrínsecos como realização pessoal com a profissional, vaidade e motivação são características que influenciaram na escolha do curso, sendo que a maioria dos pesquisados apontaram como fundamental na 
escolha da sua graduação encontrar uma carreira profissional prazerosa, como mostrou a pesquisa onde $60 \%$ dos entrevistados procuram fazer uma graduação em

\section{Referências Bibliográficas}

ADAMS, G.R. Physical Attractiveness Research: toward e Ivelopmental Social Psychology of Beauty, 1977. In: DANIEL, Natacha Massoco. Imagem corporal, influência da família e da mídia/cultura sobre o corpo e auto-estima em acadêmicas dos cursos de serviço social, educação física e psicologia da UNOESC. Trabalho de conclusão de curso. UNOESC: São Miguel do Oeste, 2007.

ALVES, Daniele Palomo Bordão; SILVA, Lucy Leal Melo. Maturidade ou imaturidade na escolha da carreira; uma abordagem psicodinâmica. Aval.psicol.; Porto Alegre, v.7, n.1, abr. 2008. Disponível em : $<$ http://pepsic.bvsalud.org/scielo.php?script=s ci_arttext\&pid=S1677-

04712008000100005>. Acesso em: 20 jul. 2012.

ALVES, Daniele Palomo Bordão; SILVA, Lucy Leal Melo. Maturidade ou imaturidade na

escolha da carreira; uma abordagem

psicodinâmica. Aval.psicol.; Porto Alegre, v.7, n.1, Disponível

em:<http://pepsic.bvsalud.org/scielo.php?scri $\mathrm{pt}=$ sci_arttext\&pid=S1677

04712008000100005>. Acesso em: 30 set. 2012.

AMARAL, A.C.S.; ANDRADE, M. R. M.; OLIVEIRA, T.P.; MADEIRA, R.H.A.; FERREIRA, M.E.C.. A cultura do corpo: nível de satisfação corporal entre escolares de diferentes faixas etárias - estudo comparativo.Juiz de Fora, v.33, n.2, p.41-45, abr./jun. 2007.

BERGAMINI, Cecília W. Motivação: mitos crenças e mal entendidos. Rev. de
Tecnologia em Cosmetologia e Estética para realizarem suas expectativas pessoais, por questões de vaidade e autoestima.

Administração de empresas; São Paulo, v.30, n.2,jun.1990. Disponível em: $<$ http://fortium.edu.br/blog/valeria_martins/fil es/2010/10/Motiva\%C3\%A7\%C3\%A3o_mito s.pdf>. Acesso em: 20 set. 2012.

BORGES,Livia de OIiveira; ALVES FILHO, Antônio.A mensuração da motivação e do significado do trabalho.Estudos de

Psicologia; Rio Grande do Norte,v.6, n.2, 2001. Disponível em: <http://www.scielo.br/pdf/epsic/v6n2/7272.pd f>. Acesso em: 02 set. 2012.

BRASIL, Ministério da Educação. Lei de diretrizes e bases da Educação Nacional, dez. 1996. Disponível em:

<http://portal.mec.gov.br/arquivos/pdf/ldb.pdf >. Acesso em: 29 agosto. 2012.

GIL, Antônio C.; Como elaborar projetos de pesquisa. São Paulo: Atlas, 2002. 175p.

MAGALHAES, Mauro; REDIVO, Andrea. Re-opção de curso e maturidade vocacional. Rev. ABOP; Porto Alegre, v. 2, n. 2, 1998 . Disponível em :< http://pepsic.bvspsi.org.br/scielo.php?script=sci_arttext\&pid= S1414-88891998000200002\&lng=es\&nrm= >. Acesso em: 25 ago. 2012.

MOURA, Cynthia Borges de; MENEZES, Mirtes Viviani. Mudando de opinião: análise de um grupo de pessoas em condição de reescolha profissional. Rev. bras. orientac.

Prof; São Paulo, v. 5, n. 1, jun. 2004 .

Disponível em

$<$ http://pepsic.bvsalud.org/scielo.php?script=s ci_arttext\&pid=S1679$33902004000100004 \& \operatorname{lng}=$ pt\&nrm=iso $>$. Acessos em: 28 ago. 2012. 
PEREIRA, Marta Cristiane Alves; FÁVERO, Neide. Motivação no trabalho da equipe de enfermagem. Latino-am Enfermagem; São Paulo, v.9, n.4.jul. 2001.Disponível em:

$<$ http://www.scielo.br/pdf/rlae/v9n4/11476.pd f>. Acesso em : 31 jul. 2012.

PONTE, Joao Pedro.Da formação ao desenvolvimento profissional. Lisboa: Universidade, 1998 - Disponível em: < www.educ.fc.ul.pt/docentes/jponte/artigospor-temas.htm >. Acesso em:21 ago.2012

SASAKI,Renata Claudine; TAVARES, Karina Jorge, VELHO, Ana Paula Machado. A moda como instituição Social. ${ }^{a}$ Encontro paraense de Moda, design e negócios, Paraná,2008 .Disponível em: < http://www.dep.uem.br/enpmoda/artigos/C02 ENPMODA.pdf>. Acesso em: 18 ago. 2012.

SILVA, Paulo José Alves Carvalho da. A dor da alma nas reflexões sobre a vaidade de
Matias aires (1952)*.Rev. Latinoam

Psicopat. Fund; São Paulo, v.12, n.2.

jun.2009. Disponível em: <http://www.scielo.br/pdf/rlpf/v12n2/v12n2a

10.pdf>. Acesso em: 10 ago. 2012.

SPARTA, Mônica; GOMES, William B. Importância atribuída ao ingresso na educação superior por alunos do ensino médio. Rev. bras. Orientac.prof; São Paulo, v. 6, n. 2, dez. 2005 . Disponível em: $<$ http://pepsic.bvsalud.org/scielo.php?script=s ci_arttext\&pid=S1679$33902005000200005 \& \operatorname{lng}=p t \& n r m=i s o>$. Acesso em: 23 jul. 2012.

TELES, M.L.S. Psicodinâmica do Desenvolvimento Humano. Petrópolis: Vozes, 2001 